\title{
Changes in Glycemic Index in Quality Protein Maize Based Flour Before and After Processing Under In Vitro Condition
}

\author{
Saloni Chauhan* and Usha Singh \\ Department of Food and Nutrition, Rajendra Prasad Central Agricultural University, \\ Pusa (Samastipur), India, 848125 \\ *Corresponding author
}

\section{A B S T R A C T}

\section{Keywords}

Glycemic index (GI), Processing, Invitromethod, Maize, Bengal gram, QPM (quality protein maize)

Article Info

Accepted:

18 October 2018

Available Online:

10 November 2018
Maize, a nutricereal can be utilized for persons in stress if properly processed. Maize is a stable human food eaten by more than a billion people around world in a variety of whole and processed form of products. The data on the glycemic index value of different varieties of foods within India is very limited. Also effect of processing on glycemic index of food is also scanty. In view of this background, the current study was undertaken to determine the effect of processing on glycemic index in QPM (quality protein maize) grain before and after incorporating whole bengal gram through in vitro method. In this study, results revealed that the alkali treated maize and boiled maize grain was lower $(69.38 \pm 0.18)$ and $(69.29 \pm 0.29)$ glycemic index as compared to roasted and control maize grain $(75.40 \pm 0.12)$ and $(80.29 \pm 0.12)$ respectively. After incorporating whole bengal gram in QPM, the level of glycemic index was found to be lower in case of boiled maize $(55.88 \pm 0.66)$ and alkali treated maize $(55.51 \pm 0.36)$ as compared to roasted maize $(63.63 \pm 0.24)$ and control maize (67.45 \pm 0.78$)$. The lower level of glycemic index in QPM after boiling and alkali treatment is recommended for persons with Diabetes, obesity and cardiovascular diseases.

\section{Introduction}

Glycemic index has proven to be a more useful nutritional concept than is the chemical classification of carbohydrate (as simple or complex, as sugars or starches, or as available or unavailable), permitting new insights into the relation between the physiologic effects of carbohydrate-rich foods and health. Several prospective observational studies have shown that the chronic consumption of a diet with a high glycemic load (GI dietary carbohydrate content) is independently associated with an increased risk of developing type 2 diabetes, cardiovascular disease, and certain cancers. Glycemic index is a measure of the effect of carbohydrates on blood sugar levels. Carbohydrates that break down quickly during digestion releasing glucose rapidly into the bloodstream, have a high GI; Carbohydrates that break down more slowly, releasing glucose more gradually into the blood stream, have a low GI. For most people, foods with a low GI have significant health benefits. These 
factors include physical entrapment, rate of digestion, food form (physical forms, particle size), type of preparation (processing and cooking method), nature of starch (amylose or amylopectin), amount and presence of fibre, fat and protein and the presence of organic acids.

A popular application of GI is for body weight management. A low-GI diet is thought to promote weight loss through reduced food intake, reduced fat storage, and increased fat oxidation. Physiological and metabolic advantages observed from consuming low GI foods are due to reduced rate of carbohydrate absorption in the small intestine. The metabolic advantages include; lower postprandial glucose rise; reduced daily insulin levels, flatter gastric inhibitory polypeptide response decreased 24 hours uninary C-peptide output, prolonged suppression of plasma free fatty acids; reduced urinary catecholamine cholesterol levels, reduced hepatic cholesterol synthesis, decreased serum uric acid levels and increased urinary uric acid excretion.

Cereal grains are the main staple food like wheat, rice and number of coarse grain which are now termed as nutricereals like maize, sorghum, bajra, ragi, barely etc. However, the nutricereals having higher nutrient content. Among all nutricereals maize is one of the staple food which contains, carbohydrate, protein, fat and appreciable amount of phosphorus, calcium and iron.

In India, rice, wheat and maize are the three important staple food crops, out of these three crops, maize is very nutritious. QPM is a cheap and alternate source of protein for the poor who do not have resources to buy eggs or meat their dietary protein requirement. QPM have superior protein quality and protein digestibility over normal maize and other cereals. QPM has improved and balanced composition of amino acids. In QPM the content of lysine and tryptophan doubled and the ratio of leucine and isoleucine reduced from $1.6-2.5$ to improve the protein quality. Maize is a major crop for livestock feed and human nutrition in a number of developed and developing countries. At global level, India ranks 4th in area and 7th in production of maize. The productivity of maize is increasing in India day by day, but the intake of maize is decreasing. Hence the risk factors are also increasing day by day. So, considering all these points in mind it had been undertaken to study the changes in glycemic index in QPM based flour before and after processing under in vitro condition.

\section{Materials and Methods}

\section{Selection of the raw material}

The most common varieties of QPM (Shaktiman-5) grain were selected for the study. Further for making the food mix with lower glycemic index bengal gram was taken as premix.

\section{Procurement of maize grains and bengal gram}

For the study, freshly harvested QPM grainvariety (Shaktiman-5) and bengal gram was collected from farmers of Bisanpur, Dighra, (District -Samastipur) in one lot. For the study, the $12 \mathrm{~kg}$ maize grains and $5 \mathrm{~kg}$ bengal gram were procured. The collected grains were cleaned by isolating damaged and unhealthy seeds and also by removing foreign matter. Ten $\mathrm{kg}$ of cleaned maize grains were divided into 4portions each of $2.5 \mathrm{~kg}$ for processing. Each portion was sub-divided for processing into triplicate. In case of bengal gram, the lot was divided into two portion for processing. Each portion was subdivided for processing into triplicate. 


\section{Processing of QPM and pulse grains}

For the study, out of four sets (in triplicate), one set was kept as such as control (in triplicate). The other three sets (each in triplicate) were kept for processing. The processing methods applied were boiling, roasting and alkali processing.

\section{Boiling of maize grains}

Maize grains (in triplicate) were boiled in double amount of water by weight for 30 minutes. Then it was oven dried for 10 hours at $60{ }^{\circ} \mathrm{C}$.

\section{Roasting of maize grains}

Maize grains were roasted at temperature at $180^{\circ} \mathrm{C}$ for 20 minutes.

\section{Alkali processing of maize grains}

Maize grains were soaked for 5 minutes in double amount of $1 \%$ lime water by weight and then heat treatment was given for 30 minutes at $85^{\circ} \mathrm{C}$. Then it was kept overnight. Next day the grains were washed 4 times and kept in oven for 10 hours at $60^{\circ} \mathrm{C}$ for drying.

\section{Processing of bengal gram grains}

Bengal gram grains were soaked for overnight ( 8 to 10 hours) then dried in sunlight and then ground into flour.

\section{Preparation of the sample}

After the application of processing methods, the control as well as processed QPM grains (all together 12 replicates) were subdivided into four sets. Similarly maize grain and pulse after processing along with the control (all together 12 replicates maize grain and 6 replicates of whole bengal gram) were subdivided into four sets and two sets. Then, the maize grains and whole bengal gram were converted into flour with the help of grinder.

\section{Results and Discussion}

\section{In vitro determination of glycemic index}

The in vitro glycemic index was determined according to the protocol given by Englyst $e t$ al., (1987). In the first phase, samples were mixed with an equal weight of water, homogenized and incubated with $\alpha$-amylase (185 U/g available carbohydrates) at $37^{\circ} \mathrm{C}$ for $15 \mathrm{~min}$ in a shaking incubator, in order to mimic the oral digestion. Subsequently, the $\mathrm{pH}$ was adjusted to 2.5 with $0.1 \mathrm{M} \mathrm{HCl}$. In cases that a food's homogenate volume was less than $2 \mathrm{ml}$, water ( $\mathrm{pH}$ adjusted to 2.5 with $0.1 \mathrm{M} \mathrm{HCl}$ ) was added up to $2 \mathrm{ml}$ and transferred in duplicates to wells in a six-well plate. In each well plate, $0.1 \mathrm{ml}$ of pepsin (porcine pepsin preparation, suspended in 4 $\mathrm{g} / 100 \mathrm{~mL}$ in $0.1 \mathrm{M} \mathrm{HCl}$,) was added and the plates were placed on a shaking incubator at $37^{\circ} \mathrm{C}$ for $2 \mathrm{~h}$, simulating the gastric phase of human digestion. After $2 \mathrm{~h}$, a cylindrical insert, with a piece of dialysis membrane fastened to one end with an elastic band was placed in each well plate. Each ring was filled with $2 \mathrm{ml} 0.1 \mathrm{M}$ PIPES buffer $\mathrm{pH} 6.5$ (piperazine-1,4-bis (2-ethane-sulfonic acid) disodium salt, simulating the gradual increase of $\mathrm{pH}$ in the human small intestine. The plates were incubated for another $30 \mathrm{~min}$, shaking at $37^{\circ} \mathrm{C}$.

The second phase of the in vitro digestion started after the end of this incubation period and lasted $120 \mathrm{~min}$. An aliquot $(0.2 \mathrm{ml})$ from the dialysate was taken $(t=0 \quad \mathrm{~min})$. Subsequently, the insert was carefully removed and $10 \mu \mathrm{L}$ of amyloglucosidase (3260 U/mL amyloglucosidase) and $0.5 \mathrm{ml}$ of a pancreatin-bile salt mixture $(0.2 \mathrm{~g}$ porcine pancreatin from porcine pancreas, and $1.2 \mathrm{~g}$ bile extract, suspended in $100 \mathrm{~mL} 0.1 \mathrm{M}$ 
$\mathrm{NaHCO}_{3}$ ) was added on to each digested sample. The cylindrical insert was placed back and the incubation continued in a shaking incubator for $2 \mathrm{~h}$, taking aliquots $(0.2 \mathrm{ml})$ every $30 \mathrm{~min}$ from the dialysate for the determination of glucose $(t=30 \mathrm{~min}, t=60$ $\min , t=90 \mathrm{~min}, t=120 \mathrm{~min}$, where $t=0 \mathrm{~min}$ is set at the start of the second phase of the in vitro digestion procedure). The digested samples $(0.2 \mathrm{ml}$ aliquots $)$ were mixed immediately with $0.8 \mathrm{ml}$ ethanol in a microcentrifuge tube and $30 \mathrm{~min}$ later the tubes were centrifuged for $10 \mathrm{~min}$ at $5000 \mathrm{rpm}$ at $20{ }^{\circ} \mathrm{C}$ to clarify the ethanol supernatant fraction before analysis of sugars. Dialyzable glucose, i.e., the concentration of glucose in the soluble and low molecular weight fraction of the digest, was tested as an index for the prediction of glycemic response. Glucose determination was performed spectrophotometrically using the dinitrosalicylic method at $562 \mathrm{~nm}$.

\section{DNS method}

Dinitrosalicylic method was given by Miller, G L 1959. This method involves the use of spectrophotometer.

1. Add $3 \mathrm{ml}$ of DNS reagent to $3 \mathrm{ml}$ of glucose sample in a tightly capped test tube. (To avoid the loss of liquid due to evaporation cover, the test tube with a piece of paraffin film if plain test tube is used.)

2. Heat the mixture at $90{ }^{\circ} \mathrm{C}$ for $5-15$ minutes to develop the red brown color

3. Add $1 \mathrm{ml}$ of a $40 \%$ potassium sodium tartrate (Rochelle salt) solution to stabilize the color.

4. After cooling to room temperature in a cold water bath, record the absorbance with a spectrophotometer at $575 \mathrm{~nm}$.
5. Then GI was calculated following the procedure of Wolever et al., (1986). These obtained values were compared with the GI of the ingredients from the literature. Glycemic index was calculated using the equations below:

6.

$$
\mathrm{GI}=\frac{\text { IAUC OF TEST FOOD }}{\text { IAUC OF REFERENCE FOOD }} \times 100
$$

\section{Data analysis of gycemic index}

The data obtained upon determination of quality parameter of QPM grains had been analyse for statistical implication by using standard deviation and paired ' $t$ ' test to find out the effect of processing methods on the glycemic index of maize flour before and after incorporating with pulse (Snedecor and Cochran, 1989).

The glycemic index of QPM grains (before and after processing) with and without whole bengal gram was determined. The data obtained on glycemic index in flour and changes in glycemic index after application of different processing methods have been presented in Table 1 and illustrated through (Fig. 1).

The freshly harvested QPM grains i.e. raw maize grains had been taken as control sample. The samples were boiled, roasted and alkali treated maize grains. It was revealed from table that the value of GI in control sample was 80.29 GI. In boiled maize grain sample was 69.29 GI and the roasted and alkali treated maize sample was 75.40 and $69.38 \mathrm{GI}$.

It can observed in Table 1 that the value of glycemic index in control QPM grain sample was highest (80.29) followed by boiled maize sample (69.29), roasted maize sample (75.40) and alkali treated maize sample (69.38). 
Table.1 Level of glycemic index in QPM and QPM based flour under various processes through in vitro method

\begin{tabular}{|c|c|c|}
\hline Maize flour sample & $\begin{array}{l}\text { Glycemic index of QPM } \\
\qquad(\text { mean } \pm \text { S.D })\end{array}$ & $\begin{array}{l}\text { Glycemic index on QPM grain + } \\
\text { Bengal gram (mean } \pm \text { S.D) }\end{array}$ \\
\hline Control (A) & $80.29 \pm 0.12$ & $67.45 \pm 0.78$ \\
\hline Boiled (B) & $69.29 \pm 0.29$ & $55.88 \pm 0.66$ \\
\hline Roasted (R) & $75.40 \pm 0.12$ & $63.63 \pm 0.24$ \\
\hline Alkali treated (D) & $69.38 \pm 0.18$ & $55.51 \pm 0.36$ \\
\hline \multicolumn{3}{|c|}{ 't' value among maize samples } \\
\hline $\mathbf{A} \times \mathbf{B}$ & $81.51^{*}$ & $46.39^{*}$ \\
\hline $\mathbf{A} \times \mathbf{C}$ & $45.32^{*}$ & $10.65^{*}$ \\
\hline$A \times D$ & $88.96^{*}$ & $54.02^{*}$ \\
\hline $\mathbf{B} \times \mathbf{C}$ & $(-) 38.33^{*}$ & (-) $24.33^{*}$ \\
\hline $\mathbf{B} \times \mathbf{D}$ & $(-) 0.48 \mathrm{NS}$ & (-) $2.81 \mathrm{NS}$ \\
\hline$C \times D$ & $67.06^{*}$ & $40.29^{*}$ \\
\hline
\end{tabular}


Table.2 Percent changes in glycemic index on quality protein maize based product as compared to quality protein maize under different processes

\begin{tabular}{|l|c|c|}
\hline \multirow{2}{*}{} & \multicolumn{2}{|c|}{ Percentage change in QPM grains } \\
\cline { 2 - 3 } & Glycemic index on QPM & $\begin{array}{c}\text { Glycemic index on QPM } \\
\text { grain (\%) }\end{array}$ \\
\hline Boiled (B) & $13.70 \downarrow$ & $17.15 \downarrow$ \\
\hline Roasted (C) & $6.09 \downarrow$ & $5.66 \downarrow$ \\
\hline Alkali treated (D) & $13.58 \downarrow$ & $17.70 \downarrow$ \\
\hline
\end{tabular}

Fig.1 Level of glycemic index in QPM (quality protein maize) and QPM based flour under various processes through in vitro method

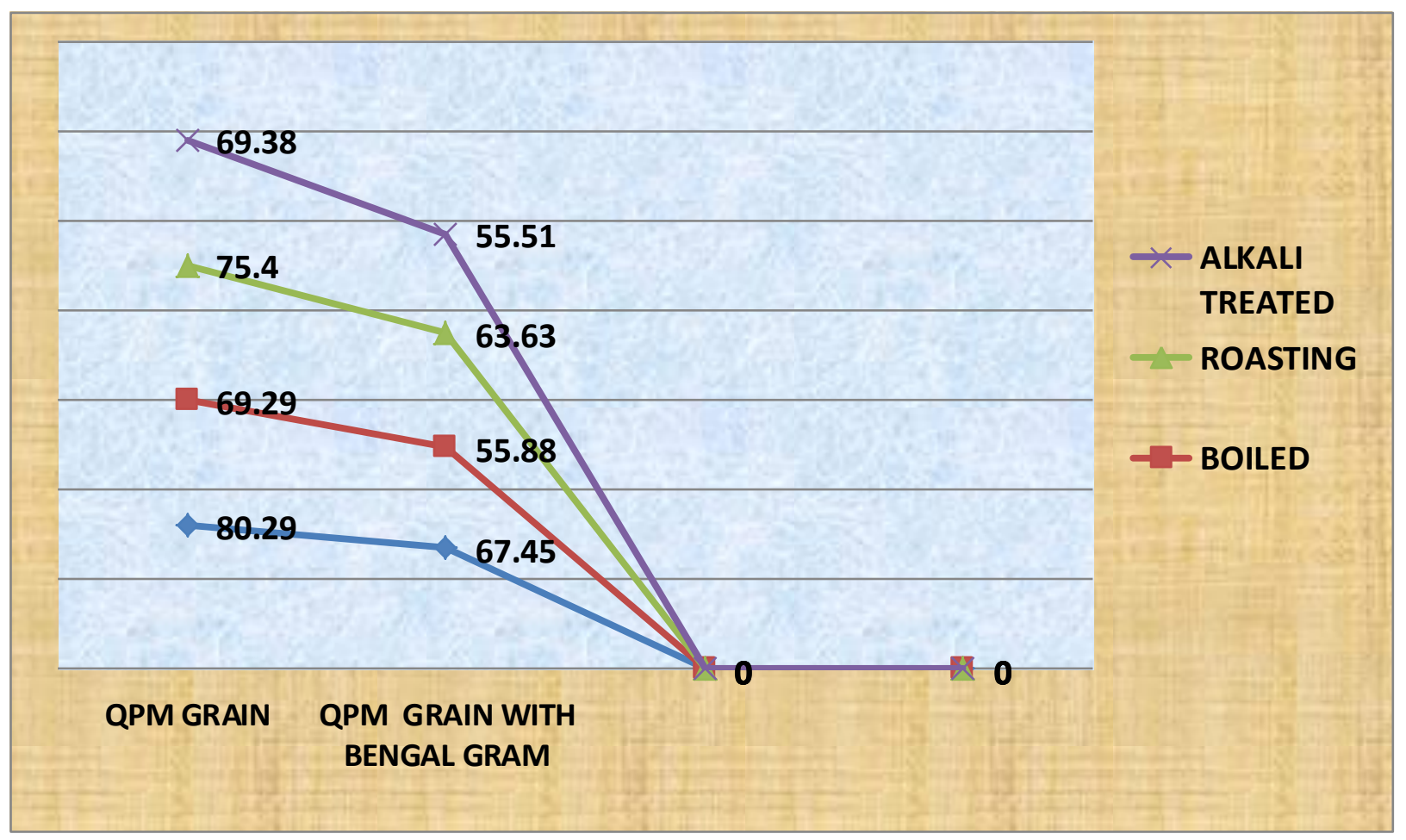


Fig.2 Percent changes in glycemic index on quality protein maize based product as compared to quality protein maize under different processes

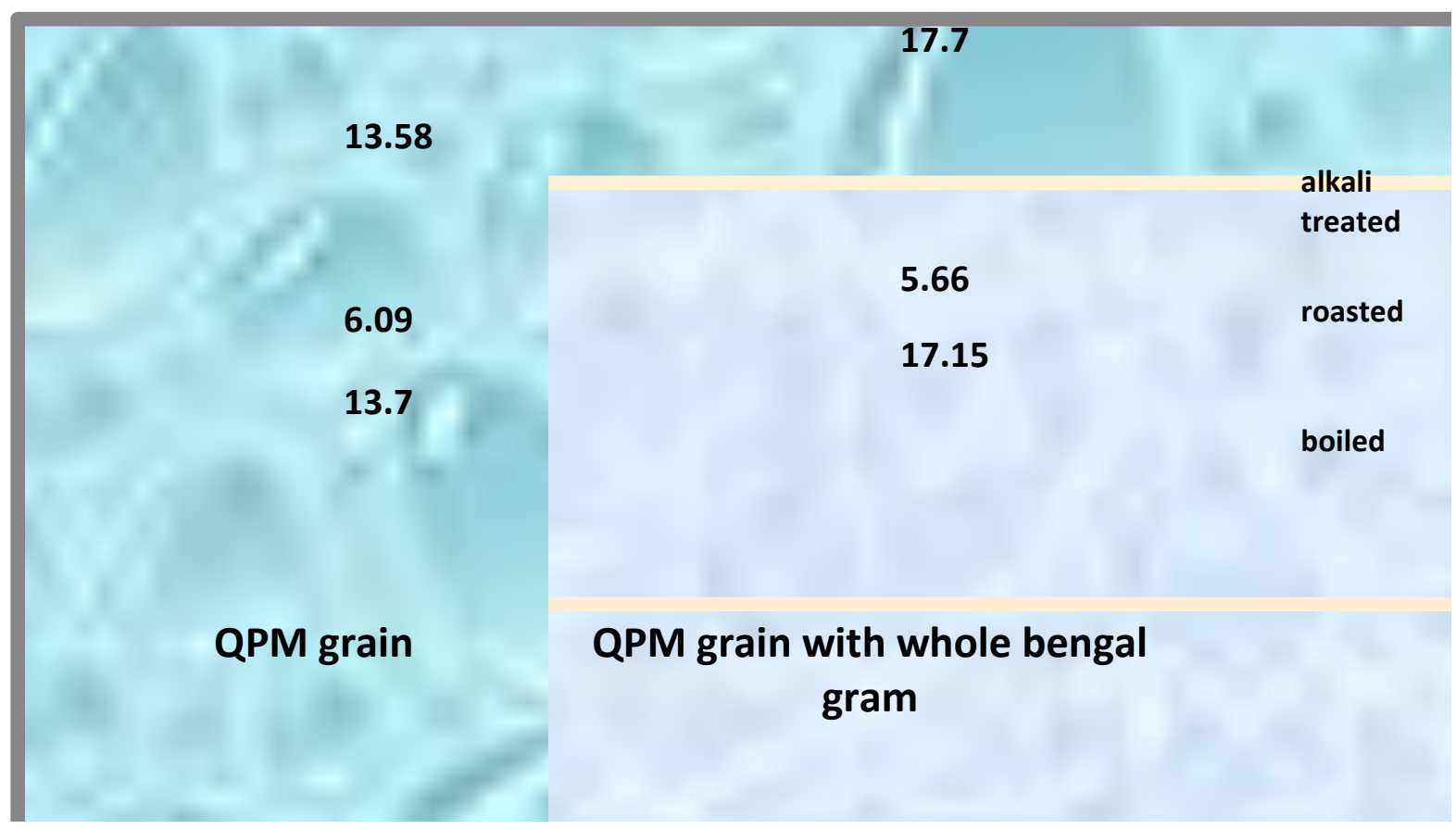

The statistical analysis clearly showed that the GI of control QPM sample was significantly higher than boiled maize sample (' $\mathrm{t}$ ' value 81.51), roasted maize sample ('t' value 45.32), lime treated maize sample ('t' value 88.96) at $1 \%$ level of probability. The boiled maize sample was found to be significantly lower than the roasted maize sample (' $t$ ' value - 38.33) at $1 \%$ level of probability. The difference between GI of boiled and alkali treated maize sample $(-0.48)$ was found to be non-significant. Roasted maize sample was significantly higher than the alkali treated maize sample ('t' value 67.06) at $1 \%$ level of probability.

In case of QPM flour with pulse from freshly harvested QPM grains before and after processing method like boiling, roasting and alkali processing has been presented in (Table 1). The freshly harvested maize grains i.e. raw maize grains had been taken as control sample.

The samples were boiled, roasted and alkali treated maize grains. It was revealed from the table that control maize flour sample with pulse was 67.45. In boiled maize flour sample with pulse was 55.88 GI. In roasted maize flour sample with pulse was 63.63 and alkali treated maize flour sample with pulse was 55.51GI.

It can be observed in (Table 1), the value of GI in control maize flour sample with pulse was highest (67.45) followed by boiled maize sample with pulse (55.88), roasted maize sample with pulse (63.63) and alkali maize treated sample with pulse (55.51).

The statistical analysis clearly showed that the GI of QPM control sample with pulse was significantly higher than the boiled maize sample with pulse (' $t$ ' value 46.39), QPM roasted maize sample with pulse (' $\mathrm{t}$ ' value 10.65), QPM alkali treated maize sample (' $\mathrm{t}$ ' value 54.02 ) at $1 \%$ level of probability. The boiled maize sample with pulse was found to be significantly lower than the roasted maize sample with pulse ('t' value -24.33) at $1 \%$ level of probability. The difference between GI of 
QPM boiled and alkali treated maize sample with pulse (' $t$ ' value -2.8) was found to be nonsignificant and QPM roasted maize sample with pulse was significantly higher than the alkali treated maize sample with pulse (' $\mathrm{t}$ ' value 40.29 ) at $1 \%$ level of probability.

\section{Percent changes in glycemic index in quality} protein maize (QPM) based product as compared to QPM under different processes

The percent change in glycemic index in maize flour after application of different processing method as compared to control sample can be observed in Table 2 and illustrated through (Fig. 2). The GI in boiled maize samples was decreased by $13.70 \%$ percent whereas it was decreased in roasted and alkali treated samples by $6.09 \%$ percent and $13.58 \%$ percent respectively.

Percent change in glycemic index in processed maize flour after incorporating whole Bengal gram can be observed in Table 2 and illustrated through (Fig. 2). The GI in boiled maize sample was decreased by $17.15 \%$ percent whereas it was decreased in roasted and alkali treated sample $5.66 \%$ percent and $17.70 \%$ percent respectively.

It can be concluded from Table 2 and Figure 2 that after processing, the value of glycemic index decreased. The value of GI of alkali treated QPM grain was lowered as compared to boiled and roasted maize grain. After incorporating whole bengal gram in QPM flour sample, it was found that the value of GI was decreased as compared to without incorporating QPM grain sample.

In conclusion, the GI found in control QPM flour sample was highest (80.29) followed by boiled QPM sample (69.29), roasted sample (75.40) and alkali treated sample (69.38). It was found that GI in control QPM sample with pulse was highest (67.45) followed by boiled sample with pulse (55.88), roasted sample with pulse (63.63) and alkali treated sample with pulse (55.51).
Hence, low glycemic index quality protein maize based food mixes is recommended in stress condition such as obesity, diabetes, heart diseases etc. and also high glycemic index quality protein maize based food mixes is recommended in case of malnutrition, given after exercise for extra energy, sports person, lactating and pregnant women for extra energy to fulfill their requirement.

\section{References}

Foster-powell, K., Holt, S.H, and Brand Miller, J.C. (2002). International table of glycemic index and glycemic load values. American Journal Clinical Nutrition.25: 5-56.

Jenkins, D. J. A., Wolever, T. M. S., Hockaday, T. D. R., Leads, A. R., Howarth, R., Bacon, S., Apling, E.C and Dilawari, J. (1977). Treatment of diabetes with guargum. Lancet. 2: 779-780.

Arvidsson-Lenner, R., Asp, N., Axelsen, M., Bryngelsson, S., Happa, E., Jarvi, A., Karlstrom, B., Raben, A., Sohlstrom, A., Thorsdottir, I and Vessby, B. (2004). Glycemic index: Relevance for health, dietary recommendations and food labeling. Scandinavian Journal of Nutrition.48: 84-94.

Wolever, T. M. S. (2006). The glycemic index: a physiological classification of dietary carbohydrate, Wallingford. UK, Cambridge, MA, CABI.

Pasupuleti, V. K and Anderson, J. W. (2008). Nutraceuticals, glycemic health and type 2 diabetes, John Wiley and Sons Ltd, Lowa, USA.

Englyst, H. $\mathrm{N}$ and Hudson, G. J. (1987).Colorimetric method for routine analysis of dietary fibre as non-starch polysaccharides. A comparison with gasliquid chromatography. Food Chemistry. 24: 63-76.

Miller, G. L. (1959). Use of dinitrosalicylic acid reagent for determination of reducing sugar. Anal Chemistry.31(3): 426.

Wolever, T. M and Jenkins, D. J. (1986). The 
use of the glycemic index in predicting the blood glucose response to mixed meals.The American Journal of Clinical Nutrition.43(1): 167-172.
Snedecor, G. W and Cochran, W.G. (1989). Statistical methods, eight edition, lowa state university press.

\section{How to cite this article:}

Saloni Chauhan and Usha Singh. 2018. Changes in Glycemic Index in Quality Protein Maize Based Flour Before and After Processing Under In Vitro Condition. Int.J.Curr.Microbiol.App.Sci. 7(11): 2613-2621. doi: https://doi.org/10.20546/ijcmas.2018.711.298 